\title{
COASTAL HYDRODYNAMIC MODELING TO SUPPORT THE RECONSTRUCTION OF BREAKWATERS AT CAP-DES-ROSIERS
}

\author{
Mathieu Roy, WSP Canada, mathieu.roy@wsp.com \\ Benoit Ruest, WSP Canada, benoit.ruest@wsp.com \\ Vincent Métivier, WSP Canada, vincent.metivier@wsp.com \\ Nicolas Guillemette, WSP Canada, nicolas.guillemette@wsp.com \\ Steve Renaud, WSP Canada, steve.renaud@wsp.com \\ Alain Drouin, Public Works and Government Services Canada, Alain.Drouin@tpsgc-pwgsc.gc.ca
}

\begin{abstract}
INTRODUCTION
The fishing harbor of Cap-des-Rosiers is located at the northeast end of the Gaspé Peninsula and is owned by Parks Canada. It is located within the Forillon National Park, at the mouth of the Whalen River. Two jetties, composed of Berlin walls, delineate the inner channel of the harbor and act as breakwaters. Despite the presence of these breakwaters, significant problems of agitation have been observed in the past within the harbor during storms.
\end{abstract}

Sedimentation is another problem that affects the fishing harbor of Cap-des-Rosiers. The sediments accumulate inside the basin, in the inner channel, as well as at the entrance to the harbor. Some of the sediment transported by the Whalen River appears to be deposited inside the basin and in the inner channel of the harbor. The coastal longitudinal drift in the area seems to contribute to the sedimentation of the entrance to the harbor. As a result, dredging of approximately 500 to $3,000 \mathrm{~m}^{3}$ of sediment has been required every 2 to 4 years since 2000. Dredging was carried out more frequently in previous decades.

The reconstruction of the breakwaters of the Cap-desRosiers harbor is planned by Parks Canada because of the advanced deterioration of the Berlin walls. It is therefore desirable to take advantage of the intervention to improve the breakwaters layout in such a way as to provide better navigation conditions and to minimize agitation and sedimentation within the harbor.

The objective of this study is to recommend concepts for the reconstruction of the breakwaters of the Cap-desRosiers harbor in order to:

- to improve the conditions of agitation inside the harbor;

- $\quad$ reduce, or at least, maintain the sedimentation conditions in and around the harbor entrance and;

- Improve, or at a least, maintain navigational conditions at the entrance and inland channel of the harbor.

Various coastal hydrodynamic and wave modeling software were used as decision making tools for this project. In the following, modelling strategies for design wave height calculation (Figure 1), wave agitation modeling (Figure 2) and hydro-sedimentary simulations (Figure 3 ) are presented for each of the above mentioned objective.

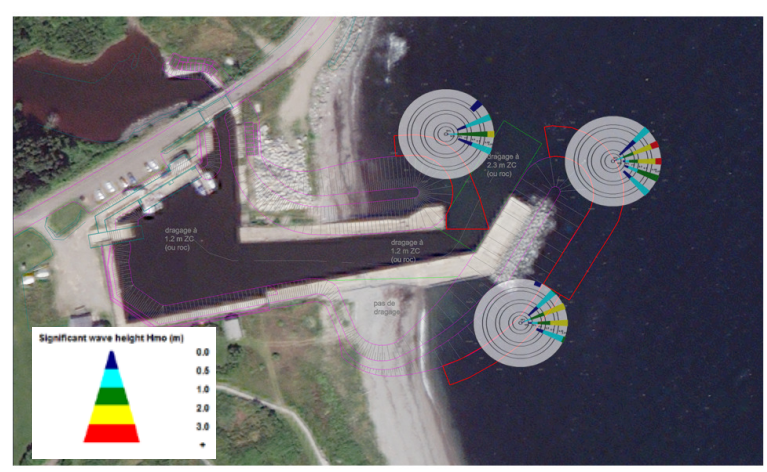

Figure 1 - Wave hindcast and design wave height calculation for the breakwaters

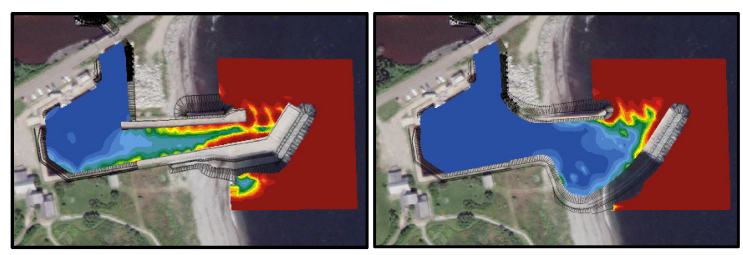

Figure 2 - Wave agitation modeling for different breakwaters layout

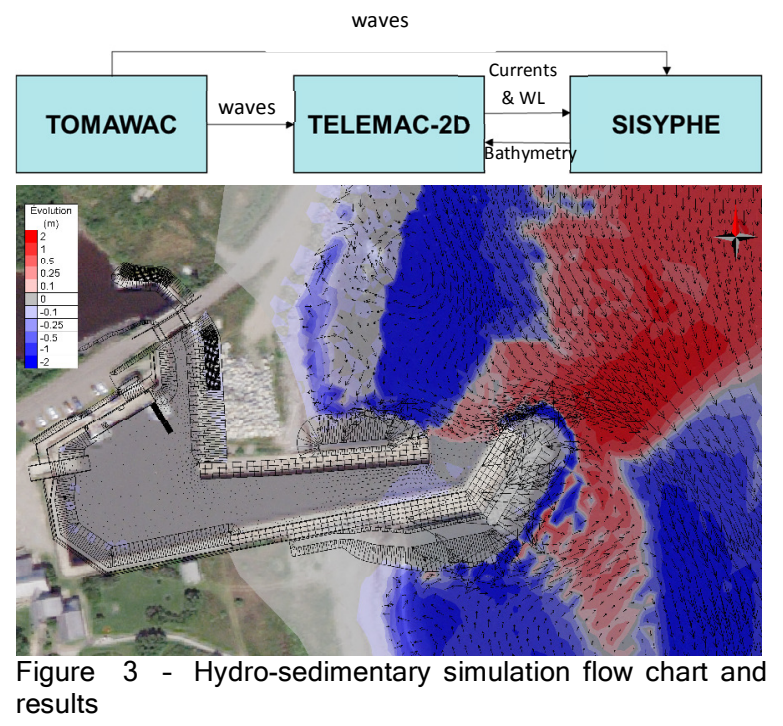

